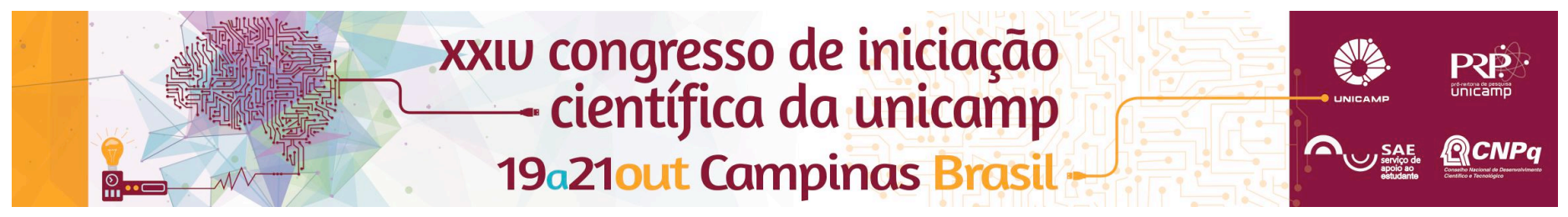

\title{
Otimização da performance de grupo em futsal através de técnicas de mensuração fisiológica e termografia
}

\section{William Moura Pitarello*, Daniella Jorge de Moura}

\section{Resumo}

O objetivo deste projeto foi otimizar o treinamento de atletas universitários de Futsal através de análises de fisiológicas, de intensidade de treino e de temperatura de superfície corporal. Até o momento observou-se que temperatura de superfície dos membros inferiores aumenta significativamente com o período de treino de futsal

\section{Palavras-chave:}

treinamento, termografia, performance.

\section{Introdução}

A Termografia é uma ferramenta não invasiva para a análise de funções fisiológicas através da temperatura de superfície. O uso da termografia na medicina do esporte é mais raro que em outras áreas apesar dos atletas estarem expostos a grande estresse físico em provas, sendo de igual importância na detecção ou prevenção de lesões (3). Por ser uma ferramenta não invasiva, torna-se possível monitorar a temperatura do corpo do atleta durante a após o movimento, detectando as mudanças na temperatura corporal decorrentes do exercício realizado. Especificamente na área do futebol, a termografia tem sido utilizada para avaliação do esforço de membros inferiores de atletas (2) e determinação da intensidade e localização do dano no músculo em condições de pôs treino. (1). O objetivo deste projeto é otimizar o treinamento de atletas universitários de Futsal através de análises fisiológicas, de intensidade de treino e de temperatura de superfície corporal

\section{Resultados e Discussão}

Um grupo de 15 atletas universitários entre 18 e 23 anos foi avaliado antes e após os treinos de futsal, que foram realizados 3 vezes por semana no período noturno.

Foram avaliados os batimentos cardíacos dos atletas em condição de repouso e imediatamente após o treino. Foram utilizados frequencimetros para aqueles que o possuíam ou auto aferição dos batimentos cardíacos nos 10 segundos pós treino de acordo com metodologia proposta por Marins et al, 1998.

As imagens termográficas foram coletadas através do Termovisor FLIR®. A distância utilizada entre o termovisor e os atletas foi sempre de $4,0 \mathrm{~m}$ de acordo com metodologia proposta por (2), utilizando a emissividade da pele humana de 0,98 . A temperatura de superfície antes do treino, foi avaliada pela manhã, em condição de repouso e conforto térmico. Após o treino a temperatura de superfície foi avaliada imediatamente após a execução do treino. Foram tiradas fotos termográficas dos membros inferiores (coxa e perna) anteriores e posteriores

Para a análise das imagens foi utilizado o software FLIR Tools / FLIR Tools+ 5.1 (5.1.15036.1001). A Figura 1 mostra a foto termográfica de um dos atletas, antes e após o treino, sendo analisada no Software Texto.

Para cada atleta, foi monitorado o tempo de treino realizado e tirada as fotos termográficas anteriores e posteriores logo após o treino além da mensuração dos batimentos cardíacos
Figura 1. Analise das imagens termográficas da parte superior da perna, após treino.

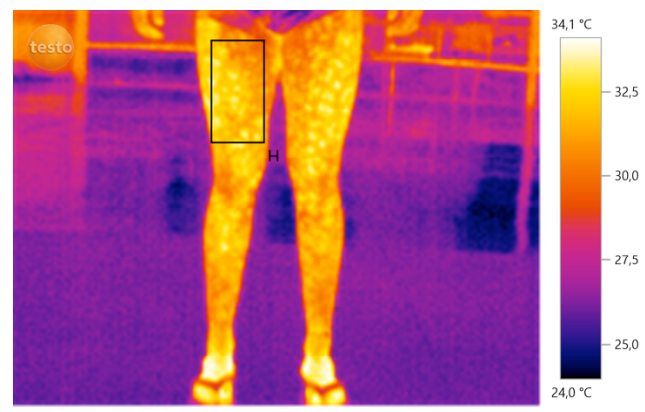

Tabela 1. Temperaturas de superfície obtidas na análise das imagens termográficas de um dos atletas.

\begin{tabular}{|c|c|c|c|c|}
\hline Repouso & Eup. Dir. & Gup. Esa. & Int. Dir. & Int: Esq. \\
\hline $\begin{array}{l}\text { Ant Med. } \\
\text { Ant. } \mathrm{M} \times \mathbf{x}\end{array}$ & $\begin{array}{l}31,10 \\
32,40\end{array}$ & $\begin{array}{l}30,90 \\
320\end{array}$ & $\begin{array}{l}30,80 \\
31,60\end{array}$ & $\begin{array}{l}30,3 \mathrm{C} \\
31,7 \mathrm{C}\end{array}$ \\
\hline $\begin{array}{l}\text { Fost Med. } \\
\text { Post. Max. }\end{array}$ & $\begin{array}{l}31,4 \mathrm{C} \\
33,2 \mathrm{C}\end{array}$ & $\begin{array}{l}31,20 \\
320\end{array}$ & $\begin{array}{l}30,30 \\
310\end{array}$ & $\begin{array}{l}30,10 \\
31,30\end{array}$ \\
\hline $\begin{array}{l}\text { Pbs Troino } \\
\text { Ant Med. }\end{array}$ & 31,90 & $31,7 \mathrm{C}$ & 31,60 & $31,3 \mathrm{C}$ \\
\hline $\begin{array}{l}\text { Ant. Max } \\
\text { Fost. Med. }\end{array}$ & $\begin{array}{l}33,90 \\
31,70\end{array}$ & $\begin{array}{l}33,50 \\
31,50\end{array}$ & $\begin{array}{l}33,60 \\
31,30\end{array}$ & $\begin{array}{l}32,50 \\
31,20\end{array}$ \\
\hline Post. M $\mathrm{XX}$ & 33.50 & $33,1 \mathrm{C}$ & 32,50 & $32,4 c$ \\
\hline
\end{tabular}

A temperatura de superfície dos membros inferiores aumenta significativamente com o período de treino de futsal.

${ }^{1}$ Bandeira, F.; Moura, M.A.A.; Souza, M.A.; Nohama, P.; Neves, E.B. Can thermography aid in the diagnosis of muscle injuries in soccer athletes?. Rev Bras Med Esporte [online]. 2012, vol.18, n.4 [cited 2015-04-03], pp. 246-251 ${ }^{2}$ Bouzas Marins, J. C.; A. de Andrade Fernandes, D. Gomes Moreira, F. Souza Silva a, C. Magno A. Costa a, E. M. Pimenta, M. Sillero-Quintana. Thermographic profile of soccer players' lower limbs. Revista Andaluza de Medicina del Esporte. Vol. 07. Núm. 01. Marzo 2014

${ }^{3}$ Bruckner, P. \& Khan, K. (2006). Fundamental principals, In: Clinical Sports Medicine. Third edition. Bruckner, P; Khan, K pp. 3-7, McGraw-Hill Medical Publishing Division, ISBN 0070278997, Canada 